Review

\title{
The role of FGF23 as an early marker of chronic renal failure
}

\author{
Andreja Figurek \\ University clinical centre of the Republic of Srpska, Banja Luka, Republic of Srpska
}

Received 04 July 2016, Accepted 16 September 2016

(C) 2016, Figurek A.

(C) 2016, Russian Open Medical Journal

\begin{abstract}
Chronic renal failure is a growing problem worldwide and it is particularly important to note that this is irreversible and progressive illness with many complications. That is why it is necessary early to be diagnosed and, as soon as possible, adequately treated. Clinical studies have shown a correlation between fibroblast growth factor 23 (FGF23) and cardiovascular risk factors, left ventricular hypertrophy and vascular calcification. Therefore, FGF23 gives the possibility for the evaluation of new therapeutic modalities in order to improve survival of patients with chronic renal disease. Further studies are needed to clarify the precise mechanism of action and regulation of FGF23 under normal circumstances and as part of chronic renal failure.
\end{abstract}

Keywords: renal failure, fibroblast growth factor 23, early marker, kidney.

Cite as Figurek A. The role of FGF23 as an early marker of chronic renal failure. Russian Open Medical Journal 2016 ; 5: e0401.

Correspondence to Andreja Figurek. Tel.: 0038765668 626. Fax: 0038751660 040. E-mail: andrejafigurek@yahoo.com

\section{Introduction}

Chronic renal failure is a growing problem worldwide and it is particularly important to note that this is irreversible and progressive illness with many complications. That is why it is necessary early to be diagnosed and, as soon as possible, adequately treated.

Mineral and bone disorder occurs in the early stages of chronic renal failure and is a strong risk for these patients. The disorder of mineral metabolism leads to early complication of chronic renal failure, which can be a risk factor for cardiovascular events [1, 2].

Clinical studies have shown a correlation between fibroblast growth factor 23 (FGF23) and cardiovascular risk factors, left ventricular hypertrophy and vascular calcification. Therefore, FGF23 gives the ability for the evaluation of new therapeutic modalities in order to improve survival of patients with chronic renal disease [3].

\section{Calcium and phosphate in chronic renal failure}

Patients with early chronic renal failure (glomerular filtration rate $(\mathrm{GFR})>30 \mathrm{ml} / \mathrm{min} / 1.73 \mathrm{~m}^{2}$ ) usually have no change in serum calcium and phosphate level. Parathyroid hormone (PTH) may be minimally elevated and recent publications have shown that FGF23, fosfaturic hormone, is clearly increased. Accordingly, in early chronic kidney weakness serum levels of phosphate and calcium are held in the normal range due to hormonal changes that make up the reduction of glomerular filtration [4].

Phosphate accumulation, reduction of the production of vitamin D and the need for additional PTH in order to maintain normal serum concentrations of calcium are events that occur at the beginning of the development of secondary hyperparathyroidism. Although at the early stages of renal insufficiency the disturbed metabolism of minerals exists, the levels of calcium, phosphate and calcitriol levels are usually normal. This is attributed to the increased secretion of PTH, which stimulates excretion of phosphate, reduced urinary excretion of calcium, and stimulates renal production of calcitriol. Therefore, it is considered that moderate increase in the value of PTH is responsible for normal calcium and phosphate. It is considered that even the normal values of serum phosphate may contribute to the development of secondary hyperparathyroidism [5] However,the increase in serum phosphate levels, even within the reference range, is associated with an increase in cardiovascular events [6] and is also associated with a progressive decrease in renal function $[7,8]$. High plasma phosphate as a risk factor for decline in renal function and mortality in pre-dialysis patients.

\section{Fibroblast growth factor 23}

FGF23 is hormon produced by osteoblasts/osteocytes in bones and which in turn acts on the kidneys to regulate the phosphate metabolism and vitamin D through the activation of the FGF23 receptor/ $\alpha$-Klotho co-receptor complex. FGF23 is primarily produced in the femur and skull [9]. It binds to the FGF23 family receptor, probably requiring a transmembrane protein Klotho, in order to facilitate interactions at the cell surface [10]. Although the FGF23 receptors are arranged in the whole body, downstream effects of FGF23 are localized in the kidney, parathyroid and pituitary glands, suggesting a primary role in these organs. FGF23 has two important and clearly describes the effect on the kidneys. Affecting the renal tubular epithelial cells, is carried downregulation of type II sodium-phosphate cotransporter, preventing reabsorption of phosphate by the tubules $[11,12]$. 
Furthermore, FGF23 suppress the expression of renal 1 alphahydroxylase, thus preventing the production of 1,25-hydroxy vitamin D by the kidneys [13]. The net effect is increased renal phosphaturia and the reduction of activation of vitamin D.

Rapid aging process, which is characterized by chronic vascular disease, demineralisation of the bones, skin atrophy and emphysema, is acknowledged in FGF23-zeros and Klotho-deficient mice [14].

Thus, FGF23 is one of the most powerful predictors of poor outcome in patients with chronic renal failure. It is possible that the increased value of FGF23 can have a negative impact through a variety of mechanisms of action independent of its role as a regulator of phosphorus homeostasis. Elevated levels of this hormone are associated with left ventricular hypertrophy, and is assumed to have a direct effect on the myocardium [15]. Serum level of FGF23 is associated with an increased mortality in dialysis patients. When it comes to the risk of mortality compared to FGF23, it is about 5-6 times, while the increase in serum phosphorus that risk 1.3-2.0 times. Moreover, an increase in risk for mortality with high levels of FGF23 is essentially independent of the phosphate level.

There is cascade of factors that contribute to the disorder of minerals and bone within chronic renal failure. In advanced chronic renal failure, phosphorus in the diet affects the PTH and FGF23, and FGF23 acts in a way that it reduces serum levels of calcitriol, which is a further stimulus for the secretion of PTH. FGF23 normally acts so as to reduce the PTH, but not in chronic renal disease where its receptor is downregulated and in parathyroid glands and in the kidney. PTH has a direct impact on bone cells to increase the expression and secretion of FGF23 and is the main reason for it's elevated level in chronic renal failure. High PTH also leads to an enhanced bone remodeling and freeing of the low molecular FGF which act on the canonical FGF receptors (FGFRs) to increase FGF23. The high levels of FGF23 act on the FGFRs in the heart, activating phospholipase C-calcineurin (PLCC), leading to left ventricular hypertrophy in these patients. High serum phosphate levels and a low level of soluble Klotho factors are involved in calcification of blood vessels in these patients [16].

\section{Cardiovascular risk}

Patients with chronic renal failure have a significant prevalence of left ventricular hypertrophy. There are many factors that present interrogation and a combination of in vitro and in vivo studies showed that the impact is direct [17]. FGF23 levels were measured in plasma samples in 3,000 of persons who were then performed echocardiography one year later as part of a prospective study - a cohort of chronic renal insufficiency (CRIC). Elevated levels of FGF23 were independently associated with hypertrophy of the left ventricle in patients with varying degrees of chronic renal insufficiency. Moreover, elevated levels of FGF23 with the start of the study were associated with an increased risk of future emerging hypertrophy of the left ventricle. Then was compared the response of isolated ventricular cardiomyocytes of neonatal rats to treatment with FGF23 anti-FGF-2 (prototype FGF). FGF23 induced left ventricular hypertrophy via activation of FGFR, but via Klotho-independent way. It is shown that the phospholipase C-calcineurin-Nuclear factor of activated T-cells (NFAT) signaling pathway is dominant axis for the development of FGF23 induced hypertrophy and not mitogen-activated protein kinase (MARK) pathway, which is activated by the activation
Klotho-FGFR1 by FGF23. In vivo, FGF23 injected directly into the myocardium or given intravenously, has led to the hypertrophy of the left ventricle in rats, while the administration is blocking the FGFR in rats with renal insufficiency caused by the $5 / 6$ nephrectomy, has led to a weakening of hypertrophy of the left ventricle. Therefore, these studies provide solid evidence that FGF23 directly induces hypertrophy of the left ventricle of the heart.

We should not forget that FGF23 is not the only factor that is altered in chronic renal weakness, which has a direct effect on the myocardium. For example, PTH directly affects myocardial cells of rats, causing early death of cells by increasing the entry of calcium into heart muscle cells and has long been thought as a uremic toxin. There is a greater interest in contributing the vitamin $D$ deficiency to the heart disease and to the effects of hyperphosphatemia, hypertension, volume overload, and changes in lipoproteins, which are among the many actual or potential uremic toxins which are well studied. But today there is considerable epidemiological and laboratory data that FGF23 is of primary importance as a cause of myocardial damage.

However, the high rate of patients who died of cardiovascular events with chronic renal failure and low efficiency of any intervention, gives us the right to adopt a new treatment strategies in chronic renal failure and to test their efficacy in clinical trials.

There are three different strategies for hyperphosphatemia, as an important risk factor for cardiovascular events: oral phosphate binders, FGF23 blockers and FGFR antagonists. For now, the only available are oral phosphate binders with their clearly demonstrated influence on the FGF23 serum levels. Moreover, while the oral phosphate binders are less specific then FGF23 blockers and FGFR antagonists, they have the advantage on the systemic phosphate and serum FGF23 reduction. Theoretically, such a dual action should allow wider vascular and cardioprotection. Although FGF23 blockers and FGFR antagonists may be accepted as a modern and disease-specific medication for hyperphosphatemia, they carry the risk of increasing the level of phosphates by inhibiting the excretion of phosphate by the kidney. Of importance would be a better understanding of organ-specific expression of the FGFRs, which would contribute to the development of selective blockers of cardiac FGFR and, thus, inhibition of hyperphosphatemia induced hypertrophy of the left ventricle, without affecting renal excretion of phosphate. In short, hyperphosphataemia is recognized as a central component in the disorder of mineral and bone as part of chronic renal failure. A significant contribution of hyperphosphatemia to the occurrence cardiovascular disease is suggested in large epidemiological studies and highlighted in the recent experimental data. Therapeutic possibilities of hyperphosphatemia should be investigated in adequately designed randomized trials [18].

\section{Vascular calcification}

Calcification may occur in the inner middle layer of the blood vessel, and as a result of thickening of the intima-media and the formation of atherosclerotic plaque with a violation of inner layer, local calcification and dyslipidemia with consequent accumulation of foam cells as the main tripping process [19]. It is interesting that atherosclerosis is limited to large and medium arteries and is generally associated with 'traditional' risk factors, such as smoking, obesity, dyslipidemia, hypertension and aging. In contrast, media 
calcification may occur in the arteries of any size and is a typical process related to age and is associated with increased stiffness and decreased flexibility of blood vessels $[20,21]$.

In patients with diabetes and/or chronic renal disease, both forms of calcification are present, but usually without differentiation between them in epidemiological studies, so it is difficult to make a strict distinction, unless the available samples of blood vessels for histological evaluation [22]. Although the initial events that lead to calcification of the intima and media differ, both reflect an active and highly regulated process that is very similar to endochondral and/or intramembranous bone formation. In addition, the inverse correlation between bone mineralization and damage to blood vessels caused by disorders of minerals, has been observed with the general population and in patients with chronic kidney disease (calcification paradox) [23].

Vascular calcification is the mark of the atherosclerotic process in chronic renal failure $[24,25]$.

Given the greater predilection calcification of blood vessels in patients with chronic kidney disease, measurement of vascular calcification may serve as a better predictor than the traditional risk factors [26].

The mechanism of vascular calcification occurrence is very complex. Regulation of vascular calcification by osteoclast regulatory factors - receptor activator of nuclear factor kappa-B ligand (RANKL), its receptor and osteoprotegerin affect the inflammatory component of atherosclerosis [27]. The release of RANKL from the endothelial cells is caused by pro-inflammatory cytokines (tumor necrosis factor - TNF, interleukin 1, etc.), or by incorporation of the activated lymphocytes to the vascular wall at the site of atherosclerosis. RANKL induces the osteoclastic transformation of monocytes and osteogenic differentiation of vascular smooth muscle cells (involved in the process of vascular calcification), and also induces the endothelial monocyte chemotactic migration to the endothelium and activation of matrix metalloproteinase-9 in monocytes (a process which is essential for the development and destabilization of the atherosclerotic plaque) $[28,29]$.

On the other hand, osteoprotegerin has anti-inflammatory and anti-atherosclerotic effect and shows opposing effects to receptor activator of nuclear factor kappaB (RANK) signaling [30].

Numerous studies have shown the involvement of FGF23 in the pathogenesis of the mineral and bone disorder, the occurrence of vascular calcification and relationship with morbidity and mortality in patients with chronic kidney disease. However, further research is needed to clarify whether FGF23 is only marker or a potential factor. Therefore, it could be a therapeutic target for the treatment of vascular calcification [31].

\section{Conclusion}

FGF23 is circulating physiological regulator of phosphate balance. In dialysis patients, measurement of serum FGF23 could become a promising laboratory test for predicting development of secondary hyperparathyroidism and response to therapy with calcitriol. Although the mechanisms of elevated FGF23 remain to be fully clarified, this factor turns into a potential uremic toxin or, in other words, a new factor in the hypothesis proposed by Slatopolski 30 years ago, to explain the pathogenesis of secondary hyperparathyroidism in patients with chronic renal failure. Further studies are needed to clarify the precise mechanism of action and regulation of FGF23 under normal circumstances and as part of chronic renal failure.

\section{Conflict of interest}

There is no conflict of interest.

\section{References}

1. Go AS, Chertow GM, Fan D, McCulloch CE, Hsu CY. Chronic kidney disease and the risks of death, cardiovascular events, and hospitalization. N Engl J Med 2004; 351: 1296-1305. PMID: 15385656. DOI: 10.1056/NEJMoa041031.

2. Kramer H, Toto R, Peshock R, Cooper R, Victor R. Association between chronic kidney disease and coronary artery calcification: the Dallas Heart Study. J Am Soc Nephrol 2005; 16: 507-513. PMID: 15601745. DOI: 10.1681/ASN.2004070610.

3. Jimbo R, Shimosawa T. Cardiovascular risk factors and chronic kidney disease - FGF23: a key molecule in the cardiovascular disease. Int $J$ Hypert 2014; 2014: 381082. DOI: 10.1155/2014/381082.

4. Rodrigez M, Felsenfeld AJ. PTH, FGF23 and early CKD. Nephrol Dial Transplant 2008; 23(11): 3391-3393. DOI: 10.1093/ndt/gfn438.

5. Felsenfeld AJ, Rodriguez M. Phosphorus, regulation of calcium and secondary hyperparathyroidism: a hypothesis to integrate a historical and modern perspective. J Am Soc Nephrol 1999; 10: 878-890. PMID: 10203374.

6. Tonelli M, Sacks F, Pfeffer M, Gao Z, Curhan G. Relation between serumphosphate level and cardiovascular event rate in people with coronary disease. Circulation 2005; 112: 2627-2633. PMID: 16246962. DOI: 10.1161/CIRCULATIONAHA.105.553198.

7. Schwarz S, Trivedi BK, Kalantar-Zadeh K, Kovesdy CP. Association of disorders in mineral metabolism with progression of chronic kidney disease. Clin J Am Soc Nephrol 2006; 1: 825-831. PMID: 17699293. DOI: 10.2215/CJN.02101205.

8. Voormolen N, Noordzij M, Grootendorst DC, Beetz I, Sijpkens YW, van Mannen JG, et al. High plasma phosphate as a risk factor for decline in renal function and mortality in pre-dialysis patients. Nephrol Dial Transplant 2007; 22: 2909-2916. PMID: 17517792. DOI: 10.1093/ndt/gfm286.

9. Yoshiko $Y$, Wang $H$, Minamizaki T, ljuin C, Yamamoto R, Suemune S, et al. Mineralized tissue cells are a principal source of FGF23. Bone 2007; 40: 1565-1573. PMID: 17350357. DOI: 10.1016/j.bone.2007.01.017.

10. Razzaque MS, Lanske B. The emerging role of the fibroblast growth factor-23-klotho axis in renal regulation of phosphate homeostasis. J Endocrinol 2007; 194: 1-10. PMID: 17592015. DOI: 10.1677/JOE-070095.

11. Shimada T, Urakawa I, Yamazaki Y, Hasegawa H, Hino R, Yoneya T, et al. FGF23 transgenic mice demonstrate hypophosphatemic rickets with reduced expression of sodium phosphate cotransporter type Ila. Biochem Biophys Res Commun 2004; 314: 409-414. PMID: 14733920. DOI: 10.1016/j.bbrc.2003.12.102.

12. Bowe $A E$, Finnegan $R$, Jan de Beur $S M$, Cho J, Levine MA, Kumar R, et al. FGF23 inhibits renal tubular phosphate transport and is aPHEXsubstrate. Biochem Biophys Res Commun 2001; 284: 977-981. PMID: 11409890. DOI: 10.1006/bbrc.2001.5084.

13. Perwad F, ZhangMY, Tenenhouse HS, Portale AA. Fibroblast growth factor 23 impairs phosphorus and vitamin D metabolism in vivo and suppresses 25-hydroxyvitamin D-1alpha-hydroxylase expression in vitro. Am J Physiol Renal Physiol 2007; 293: 1577-1583. PMID: 17699549. DOI: 10.1152/ajprenal.00463.2006.

14. Bernheim J, Benchetrit S. The potential roles of FGF23 and Klotho in the prognosis of renal and cardiovascular diseases. Nephrol Dial Transplant 2011; 26: 2433-2438. PMID: 21543658. DOI: 10.1093/ndt/gfr208. 
15. Kovesdy CP, Quarles LD. Fibroblast growth factor-23: what we know, what we don't know, and we need to know. Nephrol Dial Transplant 2013; 28(9): 2228-2236. PMID: 23625971. DOI: 10.1093/ndt/gft065.

16. Silver J, Rodriguez M, Slatopolsky E. FGF23 and PTH-double agents at the heart of CKD. Nephrol Dial Transplant 2012; 27: 1715-1720. DOI 10.1093/ndt/gfs050.

17. Faul C, Amaral AP, Oskouei B, Hu MC, Sloan A, Isakova T, et al. FGF23 induces left ventricular hypertrophy. J Clin Invest 2011; 121: 43934408. PMID 21985788. DOI: 10.1172/JCI461122.

18. Heine GH, Seiter S, Fliser D. FGF23: the rise of a novel cardiovascular marker in CKD. Nephrol Dial Transplant 2012; 27: 3072-3081. DOI: 10.1093/ndt/gfs259.

19. Ross R. Atherosclerosis-an inflammatory disease. N Engl J Med 1999; 340: 115-126. PMID: 9887164. DOI: 10.1056/NEJM199901143400207.

20. O'Neill WC, Lomashvili KA. Recent progress in the treatment of vascular calcification. Kidney Int 2010; 78: 1232-1239. DOI: 10.1038/ki.2010.334.

21. Persy V, D'Haese P. Vascular calcification and bone disease: the calcification paradox. Trends Mol Med 2009; 15: 405-416. PMID: 19733120. DOI: 10.1016/j.molmed.2009.07.001.

22. Fischer DC, Behets GJ, Hakenberg OW, Voigt M, Vervaet BA, Robijn S, et al. Arterial microcalcification in atherosclerotic patients with and without chronic kidney disease: A comparative high-resolution scanning x-ray diffraction analysis. Calcif Tissue Int 2012; 90: 465-472. PMID: 22476351. DOI: 10.1007/s00223-012-9594-5.

23. Hofbauer LC, Brueck CC, Shanahan CM, Schoppet M, Dobnig H. Vascular calcification and osteoporosis-from clinical observation towards molecular understanding. Osteoporos Int 2007; 18: 251-259. PMID: 17151836. DOI: 10.1007/s00198-006-0282-z.

24. Schwarz U, Buzello M, Ritz E, Stein G, Raabe G, Wiest G, et al. Morphology of coronary atherosclerotic lesions in patients with endstage renal failure. Nephrol Dial Transplant 2000; 15: 218-223. PMID: 10648668. DOI: 10.1093/ndt/15.2.218.

25. Jungers $P$, Massy ZA, Khoa TN, Fumeron C, Labrunie $M$, Lacour $B$, et al. Incidence and risk factors of atherosclerotic cardiovascular accidents in predialysis chronic renal failure patients: a prospective study. Nephrol Dial Transplant 1997; 12: 2597-2602. PMID: 9430858. DOI: 10.1093/ndt/12.12.2597.

26. Dellegrottaglie S, Sanz J, Rajagopalan S. Vascular calcification in patients with chronic kidney disease. Blood Purif 2006; 24: 56-62. DOI: 10.1159/000089438.

27. Collin-Osdoby P. Regulation of vascular calcification by osteoclast regulatory factors RANKL and osteoprotegerin. Circ Res 2004; 95: 1046-1057. DOI: 10.1161/01.RES.0000149165.99974.12. PMID: 15564564.

28. Glass KC, Witztum JL. Atherosclerosis: the road ahead. Cell 2001; 104 : 503-516. PMID: 11239408. DOI: 10.1016/S0092-8674(01)00238-0.

29. Gough PJ, Gomez IG, Wille PT, Wille PT, Raines EW. Macrophage expression of active MMP-9 induces acute plaque disruption in apoEdeficient mice. J Clin Invest 2006; 116: 59-69. DOI: 10.1172/JCI25074.

30. Bennett BJ, Scatena M, Kirk EA, Rattazzi M, Varon RM, Averill M, et al. Osteoprotegerin inactivation accelerates advanced atherosclerotic lesion progression and calcification in older ApoE-/- mice. Atherioscler Thromb Vasc Biol 2006; 26: 2117-2124. PMID: 16840715. DOI: 10.116/01.ATV.0000236428.91125.e6.

31. Asicioglu E, Kahveci A, Arikan H, Koc M, Tuglular S. Fibroblast growth factor-23 levels are associated with vascular calcifications in peritoneal dialysis patients. Nephron Clin Pract 2013; 124: 89-83. PMID: 24157489. DOI: 10.1159/000355859.

Authors:

Andreja Figurek - MD, Teaching Assistant, Department for Nephrology and Plasmaphereis,Clinic for Internal Diseases, University Clinical Centre of the Republic of Srpska, Banja Luka, Republic of Srpska. 